\title{
Enfoques didácticos para la enseñanza de la expresión escrita
}

\author{
Daniel Cassany
}

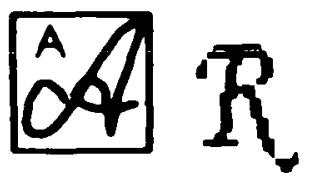

Los recientes avances de la psicología cognitiva y de la instrucción, siguiendo los procesos y las características específicas de la redacción según el contenido concreto, han venido a sumarse a las propuestas: a) Tradicional sobre la educación lingüistica en general desde un enfoque gramatical y b) Funcional, que ha contribuido en gran manera a la renovación de la enseñanza de lenguas extranjeras. El inevitable estado de perplejidad de muchos educadores de lengua en sus diversas tareas y especialidades que sin duda ha generado esta rica pero compleja oferta psicopedagógica, encuentra en esta revisión un remedio oportuno $y$ constructivo.

El presente artículo se propone esbozar a grandes rasgos los cuatro enfoques metodológicos con que puede enseñarse la expresión escrita. Para hacerlo nos basamos en los cuatro enfoques que establece Shih (1986) para le enseñanza del inglés como segunda lengua. Nuestro trabajo desarrolla notablemente esta distinción, trazando las líneas teóricas de cada planteamiento y presentando la práctica concreta de cada uno. De esta forma, la descripción de los enfoques es válida para la enseñanza de la expresión escrita en general, sin distinción de si se trata de una lengua uno o dos.

Los cuatro enfoques didácticos que se exponen son:

i) enfoque basado en la GRAMATICA

ii) enfoque basado en las FUNCIONES

iii) enfoque basado en el PROCESO

iv) enfoque basado en el CONTENIDO

Para cada enfoque se tratan los siguientes puntos:

1) Origen e influencias. ¿Cómo nace cada enfoque? ¿En qué contexto se desarrolla? ¿Qué relaciones tiene con otras disciplinas como la lingüística, la psicología o la pedagogía? 
2) Características generales. ¿̨Cuáles son sus características principales? ¿En qué se diferencia de los otros enfoques, sobre todo de los anteriores? ¿En qué modelo o teoría lingüística se fundamenta?

3) Currículum o programación de curso. ¿Cuáles son los contenidos que se enseñan? ¿Cómo se estructuran? ¿Qué modelos lingüísticos ofrece?

4) Práctica y ejercicios en clase. ¿Cómo funciona una clase? ¿Qué tipo de ejercicios se realizan? ¿Cómo y qué se corrige?

5) Ejemplo contrastado. Un ejercicio sobre el mismo ítem lingüístico y en mismo punto del proceso de aprendizaje, según cada enfoque.

6) Bibliografía. Algunas referencias bibliográficas orientativas y necesariamente incompletas.

\section{ENFOQUE BASADO EN LA GRAMATICA}

1) Nace en el contexto escolar de la enseñanza de la expresión escrita en la lengua materna (o lengua 1), y luego se traspasa y adapta para la enseñanza de la escritura en lengua 2 . La idea básica es que para aprender a escribir se tiene que dominar la gramática de la lengua (las reglas que la construyen, la esencia, la estructura, la organización formal subyacente, etc.). El núcleo de la enseñanza lo constituye precisamente este conjunto de conocimientos gramaticales sobre la lengua: sintaxis, léxico, morfología, ortografía, etc., obviamente, la influencia más importante que recibe este enfoque proviene del campo de la lingüística o de la gramática.

Se basa en la antiquísima y fecunda tradición de investigación en gramática, que arranca de los griegos y llega hasta la moderna lingüística, pasando por los gramáticos latinos, la escolástica, los gramáticos de Port Royal, la lingüistica o gramática comparada, el estructuralismo, el generativismo y la lingüística del texto. El modelo gramatical que ofrece varía según cuál sea la corriente de investigación que sustente el enfoque. En general, podemos establecer dos grandes modelos: el modelo oracional, que se basa en los estudios de gramática tradicional, y el modelo textual o discursivo, que se fundamenta en la lingüística del texto, también conocida como gramática del discurso.

2) En general, la lengua se presenta de una forma homogénea y prescriptiva. Por una parte, es homogénea porque no se tiene en cuenta la realidad dialectal de la lengua ni tampoco el valor sociolingüístico de cada palabra. Se ofrece un solo modelo lingüístico al alumno, que suele corresponder al estándar neutro y formal de la lengua (el dialecto más hablado de ésta, o el que tiene más difusión e importancia sociolingüística). Raramente se ofrecen ejemplos de variedades dialectales distintas y, si se hace, reciben un tratamiento muy erudito y poco práctico; se presentan como particularidades de la lengua (casi como «curiosidades») y no como formas lingüísticas válidas en determinadas situaciones. Asimismo, la presencia de registros o niveles de formalidad distintos es muy limitada. El alumno suele aprender sólo las estructuras y el léxico más formal y neutro; la lengua coloquial e incluso vulgar nunca aparece. Por otra parte, el modelo lingüístico también es prescriptivo, y no descriptivo o predictivo. Los alumnos aprenden aquello que debe decirse, lo que dicen los libros de gramática: la 
normativa. Lo importante es que sepan distinguir lo que es correcto y lo que es incorrecto.

En el modelo oracional, la enseñanza se centra básicamente en el ámbito de la oración: las categorías o partes de la oración, la concordancia, la ortografía, etc. En cambio, en el modelo textual, los contenidos abastan el texto o el discurso completo: se enseña a construir párrafos, a estructurar lógicamente la información del texto, a escribir una introducción y una conclusión, etc.

En el modelo oracional más tradicional, los modelos lingüísticos que se ofrecen suelen ser clásicos literarios, seleccionados y adaptados al nivel. Los libros que siguen este enfoque ofrecen una buena muestra de los autores más importantes de la lengua objeto de aprendizaje. De esta forma, se relaciona el aprendizaje de la lengua con el estudio de la literatura; se trata de una unión "también muy tradicional que después, en enfoques más modernos, se ha abandonado (o, para decirlo más exactamente, se ha replanteado con soluciones variadas: aprender una lengua implica entrar no sólo en su literatura, sino también en toda su cultura; debemos separar la enseñanza de la lengua de la cultura, de modo que los métodos deben ser culturalmente neutros o internacionales, etc.).

3) El currículum o la programación del curso se basa en los contenidos gramaticales. Estos varían según la corriente gramatical que se siga. En un enfoque tradicional, los alumnos aprenden básicamente ortografía (acentuación, v/b...), morfología (conjugación de verbos, género y número en los nombres...), sintaxis (subordinadas, concordancia...) y léxico (morfolexicología, enriquecimiento del léxico...). En un enfoque más moderno, basado en la lingüística del texto, se estudian aspectos como la adecuación (nivel de formalidad, registro, presentación del texto...), cohesión (elipsis, pronominalización, puntuación...), la coherencia interna y externa de los textos (organización de la información, párrafos...), su estructura, etc. Cada unidad didáctica, lección o apartado trata uno de estos puntos, de manera que al acabar el curso se haya tratado globalmente toda la gramática.

La forma de estructurar estos contenidos también puede variar. Las propuestas tradicionales suelen ser más analíticas y se asemejan a la forma que presenta los contenidos un libro de gramática: separan los diversos niveles de análisis de la lengua y proceden ordenadamente, tratando primero la ortografía, después la morfología, la síntaxis y el léxico. En cambio, las propuestas más modernas suelen ser holísticas y no se preocupan tanto por una ordenación lógica, como por facilitar al alumno un aprendizaje global de la lengua. De este modo, interrelacionan los contenidos de niveles de análisis distintos entre ellos en cada unidad o lección.

4) En la clase, el enfoque funciona de la forma siguiente:

1. Se explica un ítem lingüístico (el profesor lo explica, se lee en el libro de texto, etc.), de una forma teórica y luego se ponen ejemplos. Los alumnos comprenden la explicación.

2. Se hacen prácticas mecánicas. Los alumnos ejercitan el ítem nuevo en situaciones controladas y en pequeños contextos (palabras, frases...).

3. Se hacen prácticas abiertas. Los alumnos ejercitan el item en situaciones no controladas (redacciones) y contextos más globales.

4. El profesor corrige los ejercicios de los alumnos. 
Por ejemplo, con un modelo oracional:

1. El profesor explica las estructuras de comparación y los adjetivos comparativos y superlativos. Pone ejemplos con palabras y frases: $X$ es mejor/peor que $Y, X$ es más/menos alto que $Y, X$ es tan alto como $Y, X$ es altisimo, blanquísimo...

2. Los alumnos completan unas frases preparadas con las palabras anteriores. Después escriben algunas oraciones haciendo comparaciones entre los alumnos de la clase.

3. Los alumnos escriben una redacción sobre el tema de pasar las vacaciones en la playa o en la montaña. Tienen que utilizar los ítems aprendidos.

4. El profesor corrige la redacción. Corrige sólo la gramática.

Y otro ejemplo con un modelo textual:

1. El profesor explica la estructura lógica del texto descriptivo: la ordenación espacial (de arriba a abajo, de general a concreto, de izquierda a derecha...), el uso de adverbios de lugar (dentro, fuera, debajo...), y locuciones que ordenan el discurso en el espacio (a la izquierda, en primer término...). Los alumnos leen algunos ejemplos de descripciones que utilizan estos recursos.

2. Los alumnos completan algunos textos con las palabras anteriores. Acaban descripciones ya empezadas, transforman descripciones cambiando la ordenación, etc.

3. Los alumnos escriben una descripción sobre un tema u objeto $\mathrm{X}$, utilizando los recursos lingüísticos anteriores.

4. El profesor corrige la redacción. Corrige sólo la gramática.

Otros ejercicios típicos de este enfoque son el dictado en su forma tradicional (el profesor dicta y los alumnos apuntan), la redacción de temas variados, ejercicios de respuesta única (rellenar vacíos, poner acentos, conjugar verbos...), transformación de frases (relativos, voz activa y pasiva...), etc.

Finalmente, la corrección es otro aspecto más que caracteriza cada enfoque. En este caso, el profesor corrige básicamente los errores gramaticales que han cometido los alumnos. Le interesa que los textos que escriban éstos sean correctos según la norma establecida. En cambio, no tiene en cuenta otros parámetros como la originalidad, la claridad de las ideas, la estructura, el éxito comunicativo, el grado de desarrollo del texto, etc.

5) Siguiendo con el mismo ejemplo de las estructuras de comparación y los adjetivos, una posible actividad final sería la siguiente:

Escribe una redacción sobre el tema siguiente: «Ventajas y desventajas de vivir en un pueblo o en una ciudad".

6) La mayoría de métodos de expresión escrita, de libros de texto y de manuales escolares de lengua uno y lengua dos sigue este enfoque. En el contexto de la enseñanza del español como segunda lengua, un buen ejemplo es Sánchez, Cabré y Matilla (1975). 


\section{ENFOQUE BASADO EN LAS FUNCIONES}

1) Nace en el contexto de la enseñanza de una segunda lengua y, en concreto, en el seno de una metodología: la comunicativa. Sigue la tradición de métodos nocional-funcionales de L2, desarrollados en Europa durante los años sesenta, en los cuales lo más importante es enseñar una lengua para usarla, para comunicarse. Este tipo de métodos tiene su origen en la filosofía del lenguaje (Wittgenstein, Austin, Searle, etc.), y en la concepción funcionalista de la lengua que desarrolló ésta. También recibe influencias de la sociolingüística, de los primeros trabajos sobre lingüística del texto y, en el campo de la didáctica, de los movimientos de renovación pedagógica y de enseñanza activa.

Según este punto de vista, la lengua no es un conjunto cerrado de conocimientos que el alumno tenga que memorizar, sino una herramienta comunicativa útil para conseguir cosas: pedir un café en un bar, leer el periódico, expresar los sentimientos, pedir información, mostrar amabilidad, etc. La acción concreta con la que se consigue algún objetivo se llama acto de habla y consiste en la codificación o decodificación de un texto lingüístico. El conjunto completo de actos de habla es el conjunto de cosas que pueden conseguirse con la lengua y puede clasificarse con grandes grupos genéricos de funciones: saludar, pedir turno para hablar, excusarse, expresar la opinión, etc. Estas funciones se relacionan con los recursos lingüísticos correspondientes (las nociones): léxico, estructuras, conceptos abstractos, etc., y constituyen los contenidos y los objetivos de un curso comunicativo de lengua.

En el aula se enseña la lengua desde este punto de vista. El objetivo de una clase o lección es aprender a realizar una función determinada en la lengua que se aprende. La metodología es muy práctica en un doble sentido: por una parte, el contenido de la clase son los mismos usos de la lengua, tal como se producen en la calle (y no la gramática abstracta que les subyace); por otra, el alumno está constantemente activo en el aula: escucha, lee, habla con los compañeros, practica, etc. Por ejemplo, los alumnos escuchan realizaciones de una función determinada, las comprenden, las repiten y empiezan a practicarlas, de manera que subconscientemente aprenden el léxico y la gramática que aparecen en ellas.

Los primeros ejemplos de este enfoque se desarrollaron en la enseñanza del inglés y del francés como segunda lengua para principiantes o para estudiantes de primeros niveles. Tratándose de alumnos con necesidades básicamente orales, estos cursos dieron un tratamiento muy limitado a la expresión escrita. De hecho, no es hasta principios de los años ochenta, cuando empiezan a desarrollarse métodos exclusivos de expresión escrita con estos planteamientos (Johnson, 1981). En ellos, se incorporan algunos de los hallazgos más importantes de la linguística del texto, como son los conceptos sobre las propiedades del texto (coherencia, cohesión, adecuación, etc), o las tipologías de textos o los géneros del escrito. Estas últimas son básicas para la programación de estos manuales, puesto que sustituyen al concepto inicial de función o acto de habla. El concepto de tipo de texto es mucho más operativo en la lengua escrita que no el de función; por ejemplo, la lengua dispone de muchas palabras para referirse a tipos de texto 
escrito (carta, nota, aviso, instancia, examen, diligencia, artículo...), que no tienen correspondencia en la lengua oral.

2) Lo más importante de este enfoque es el énfasis en la comunicación o en el uso de la lengua, contraponiéndolo al enfoque gramatical anterior, en el que lo importante era la estructura de la lengua, las reglas de gramática. Esta idea central subyace a todas las demás características:

- Visión descriptiva de la lengua, opuesta a la visión prescriptiva anterior. Se enseña la lengua tal como la utilizan los hablantes (con todas sus variaciones, imperfecciones e incorrecciones), y no como debería ser. No se enseña lo que es correcto y lo que es incorrecto, sino lo que realmente se dice en cada situación, sea esto normativo o no, aceptado por la Real Academia de la Lengua o no. Se sustituye el binomio correcto/incorrecto por el de adecuado/inadecuado. De esta forma se tiene en cuenta el contexto lingüístico en que se utiliza la lengua: una determinada forma gramatical no es correcta o incorrecta per se, según los libros de gramática, sino que es adecuada o inadecuada para una determinada situación comunicativa (un destinatario, un propósito, un contexto, etc.). Por ejemplo, el uso no normativo del leismo es inaceptable en una situación académica y formal (conferencia, artículo...), pero puede ser muy adecuado para un uso coloquial (una carta a un familiar).

- Varios modelos lingüísticos: dialectos y registros. La lengua no es monolítica y homogénea, tiene modalidades dialectales $\mathrm{y}$, además, niveles de formalidad y de especialidad variados. Un curso de lengua debe ofrecer modelos lingüísticos variados: un alumno debe poder entender varios dialectos de la misma lengua y, también, dentro del estándar que tiene que dominar productivamente, ha de poder utilizar palabras muy formales y otras más coloquiales. Así, en el terreno de la expresión escrita son muy importantes las variaciones sociolingüísticas debidas al grado de especialización del lenguaje: un alumno que aprende a escribir debe conocer la diferencia entre cómo es el lector, el perfil del destinatario o las características psicosociológicas del receptor del mensaje.

- Materiales ¿reales o realistas? Los textos que se utilizan para la clase deben ser reales o, como mínimo, verosímiles. De esta forma se garantiza que lo que se enseña en clase es lo que realmente se utiliza en la calle.

- Atención especial a las necesidades comunicativas de cada alumno. Cada alumno tiene necesidades comunicativas distintas, de modo que deberá aprender funciones y recursos lingüísticos distintos. Cada grupo requiere una programación específica para él. Por ejemplo, es muy diferente enseñar español a un grupo de extranjeros que trabajan en el país, que a un grupo de turistas. Los dos grupos exigen programaciones particulares.

En este punto la diferencia entre este enfoque y el anterior es sustancial. Mientras en el primero se enseña siempre la misma gramática, sea cual sea el alumno, en el segundo se enseñan y se aprenden funciones diferentes según el destinatario.

3) En los métodos nocional-funcionales, la programación se basa en un conjunto de funciones o actos de habla. Estos varían de un curso a otro, pero coinciden en las funciones básicas de comunicación: presentarse, pedir información, excusarse, etc. En los métodos exclusivos de lengua escri- 
ta, la programación se basa en la tipología de textos desarrollada por la lingüística del texto. Cada lección trata de un tipo de texto distinto, de forma que al final del curso se hayan tratado los más importantes o aquéllos que piden los alumnos y que van a utilizar en su vida real.

Se suelen utilizar varias tipologías de textos. Dos de las más conocidas son:

1. Basada en los ámbitos de uso:

- Ambito personal: diario, notas, agenda...

- Ambito familiar y de amistades: cartas, postales, invitaciones...

- Ambito laboral: informes, cartas, currículums...

- Ambito académico: redacciones, apuntes, resúmenes...

- Ambito social: anuncios, cartas y artículos en la prensa...

2. Basada en la función, siguiendo la propuesta de J. M. Adam (1985): orales.

- Textos de conversación: diálogos escritos, transcripción de textos

- de descripción: de objetos, personas...

- de narración: cuentos, chistes...

- de instrucción: recetas de cocina, instrucciones de uso...

- de predicción: horóscopo, futurología...

- de exposición: lección, ensayo...

- de argumentación: opinión, defensa de tesis...

- de retórica: poesía, usos lúdicos...

Trabajando en esta línea de tipologías o géneros textuales, Serafini (1985) presenta un análisis muy interesante de textos, funciones de escritura y habilidades cognitivas, con el objetivo de elaborar un curriculum progresivo de la expresión escrita. Su propuesta es muy interesante y supera los límites del enfoque funcional para penetrar en el campo de las operaciones cognitivas, que ya pertenece al tecer enfoque didáctico.

4) En una clase se actúa de la siguiente forma:

1. Se presentan varios ejemplos reales o verosímiles de un determinado tipo de texto y se hace una lectura comprensiva de los mismos.

2. Se analizan los modelos, se comparan entre ellos para extraer las características generales del tipo de texto: partes de la estructura, estilo y fraseologia, tipo de información que incluye, etc.

3. Prácticas cerradas de producción escrita; los alumnos trabajan con textos preparados en tareas preparatorias y parciales: rellenar los vacíos de un texto, añadir información, escribir el final, cambiar la persona gramatical, etc.

4. Prácticas comunicativas: dado un contexto o una situación determinada, los alumnos escriben un texto completo.

5. El profesor corrige los trabajos.

Por ejemplo, una clase con el objetivo de enseñar a escribir cartas familiares:

1. Los alumnos leen tres o cuatro cartas familiares, seleccionadas por su variedad de estilos, registros, tonos y recursos lingüísticos utilizados. 
Los ejercicios de lectura son comunicativos: lo más importante es comprender el significado y la función del texto.

2. Los alumnos comparan entre sí los textos, a partir de un cuestionario. Se fijan en la estructura típica de una carta (membrete, introducción, cuerpo y conclusión), en el registro coloquial, en las expresiones de cortesía (querido, amigo, apreciado, etc.).

3. Los alumnos realizan varios ejercicios de práctica:

- Carta con cloze de formas verbales.

- Cambiar el registro de una carta muy vulgar. Pasarlo a lenguaje familiar, sin vulgarismos ni palabrotas. po de carta.

- Escribir la introducción y la conclusión para un determinado cuer-

4. El profesor expone una determinada situación para que los alumnos escriban una carta familiar: quieren organizar un viaje y tienen que conseguir acompañantes escribiendo algunas cartas a amigos y familiares. La exposición de la situación se hace con materiales varios: publicidad de viajes, mapas, excursiones, etc.

Otros ejercicios típicos de este enfoque son la reparación, la manipulación y la transformación de textos: cambiar el punto de vista, completar un fragmento inacabado, restituir un párrafo perdido, cohesionar las frases inconexas y desordenadas de un texto, cambiar el registro, etc.

Respecto a la corrección, se rige por parámetros estrictamente comunicativos. El profesor corrige básicamente los errores que dificultan la comprensión y que podrían enturbiar el significado del texto. Teóricamente, los errores gramaticales que no tengan valor comunicativo no se corrigen; pero a la práctica se impone el criterio de corregir aquellos errores importantes y reiterativos de la estructura, tengan implicaciones en la comunicación o no.

Finalmente, un último aspecto importante de la clase son las ayudas de motivación y estimulación para los alumnos que no saben qué escribir. El profesor procura buscar temas que sean interesantes $\mathrm{y}$, además, prepara ejercicios previos a la redacción, de forma que el alumno sepa qué escribir y esté interesado en hacerlo. Estos ejercicios pueden consistir en leer un texto introductorio sobre un tema, hacer un debate o una discusión previos, etc.

5) El mismo ejercicio sobre las ventajas de vivir en el campo o en la cidudad, adaptado a este enfoque funcional sería el siguiente:

Tu sobrino, que reside en Madrid, tiene una oferta de trabajo en Melgar de Abajo (Valladolid). No sabe si debe aceptarla, porque siempre ha vivido en una gran ciudad y no conoce el campo. Escríbele una carta para contarle tu opinión sobre el tema.

El contenido del texto y los recursos gramaticales son los mismos que en el ejercicio del primer enfoque, pero aquí existe un contexto comunicativo real. El tema de redacción se ha convertido en una carta para un sobrino. Las diferencias son evidentes: 


\section{ENFOQUE \\ GRAMATICAL}

Texto:

contexto:

motivo:

receptor:

Al ser la redacción un tipo de texto que sólo existe en el aula, el ejercicio nunca puede ser comunicativo. En cambio, al proponer un motivo, un propósito y un receptor verosímiles al mismo texto, el ejercicio se convierte en una situación de comunicación posible. El alumno tiene que buscar el registro adecuado, tiene que estructurar el texto según las convenciones establecidas y tiene que decidir qué es lo más importante que puede escribir y cómo.

6) Son buen ejemplo de este enfoque los métodos de español lengua dos Equipo Avance (1986) y Equipo Pragma (1984 y 1985). En lengua uno, destacaría tres ejemplos en catalán: Cassany et al. (1987), Coromina (1984) y Bordons et al. (1988 y 1989), con propuestas de programación muy distintas. $\mathrm{Y}$ todo con permiso de un clásico inglés: Johnson (1981).

\section{ENFOQUE BASADO EN EL PROCESO}

1) A partir de los años setenta se desarrolló en Estados Unidos un conjunto de investigaciones sobre el proceso de producción o composición de textos escritos. Un grupo de psicólogos, maestros y pedagogos que impartían cursos de expresión escrita para estudiantes americanos o extranjeros, en los colleges y universidades privadas, empezaron a analizar lo que hacían sus alumnos antes, durante y después de escribir el texto. Estos profesores estaban muy decepcionados con los métodos corrientes que utilizaban en sus clases, porque no ofrecían resultados satisfactorios en sus cursos. Los métodos de investigación que utilizaban eran muy variados: la observación, la grabación con vídeo, el análisis de los borradores que escribían los alumnos, entrevistas con éstos, tests de capacidad de expresión escrita, etc.

Los resultados de las investigaciones sugerían que los escritores competentes (los alumnos que obtenían buenos resultados en los tests) utilizaban una serie de estrategias o habilidades cognitivas para escribir que eran desconocidas por el resto de los alumnos (los que sacaban malas notas en los tests). Este hallazgo significó el reconocimiento que para escribir satisfactoriamente no es suficiente con tener buenos conocimientos de gramática o con dominar el uso de la lengua, sino que también es necesario dominar el proceso de composición de textos: saber generar ideas, hacer esquemas, revisar un borrador, corregir, reformular un texto, etc. El conjunto de estas estrategias constituye lo que se llama, de una forma un poco 
tosca, el perfil del escritor competente. Este es el que tiene en cuenta a su lector, escribe borradores, desarrolla sus ideas, las revisa, reelabora el esquema del texto, busca un lenguaje compartido con el lector para expresarse, etc. El siguiente esquema resume este perfil:

Diferencias de comportamiento entre escritores competentes e incompetentes

\section{COMPETENTES}

- Conciben el problema retórico (el ejercicio) en toda su complejidad, incluyendo nociones sobre la audiencia, la función comunicativa y el contexto.

- Adaptan el escrito a las características de la audiencia.

- Tienen confianza en el escrito.

- Normalmente, no quedan satisfechos con el primer borrador. Creen que la revisión es una forma de construir el significado del texto. Revisan incansablemente la estructura y el contenido.

- Están preparados para dedicarse selectivamente a las distintas tareas que forman la composición, según cada situación.

\section{INCOMPETENTES}

- Conciben con extrema simplicidad el problema, sobre todo en términos de jotro ejercicio de redacción!

- No tienen idea de la audiencia.

- No la tienen. No valoran la letra impresa.

- Fácilmente quedan satisfechos con el primer borrador. Creen que revisar es sólo cambiar palabras, tachar frases y perder el tiempo. Revisan sólo palabras sueltas. Les da mucha pereza revisar.

- Generalmente intentan hacerlo todo bien en el primer borrador. Se concentran en la elección de palabras y en la puntuación incluso durante las primeras etapas, cuando los escritores competentes trabajan en el contenido.

Fassler et al. (1982)

En conjunto, estas investigaciones y el enfoque general en la didáctica de la expresión escrita reciben mucha influencia de la psicología cognitiva, así como de otras ramas del saber como los estudios y las técnicas de creatividad o los métodos de solución de problemas y la heurística. Por otra parte, en lo que se refiere a la didáctica, también se nota cierta influencia de la pedagogía humanista o de los enfoques que destacan la dimensión humana y global del alumno.

2) Este enfoque pone el énfasis en el proceso de composición, en contraposición a los anteriores, que premiaban el producto acabado y listo. Lo importante no es enseñar sólo cómo debe ser la versión final de un escrito, sino mostrar y aprender todos los pasos intermedios y las estrategias que 
deben utilizarse durante el proceso de creación y redacción. El alumno muchas veces piensa que escribir consiste en rellenar con letras una hoja en blanco; nadie le ha enseñado que los textos escritos que él lee han tenido antes un borrador, y que su autor ha tenido que trabajar duro para conseguirlo: que ha hecho listas de ideas, que ha elaborado un esquema, un primer borrador, que lo ha corregido y que, al final, lo ha pasado a limpio. Según este enfoque lo más importante que debe enseñarse es este conjunto de actitudes hacia el escrito y las habilidades correspondientes para saber trabajar con las ideas y las palabras.

En consecuencia, en el aula el énfasis debe ponerse en el escritor, en el alumno, y no en el texto escrito. En los cursos tradicionales se enseña cómo debe ser el producto escrito: cuáles son las reglas de gramática, qué estructura debe tener el texto, la ligazón de las frases, la selección del léxico, etc. En cambio, este enfoque pretende enseñar al alumno a pensar, a hacer esquemás, a ordenar las ideas, a pulir la estructura de la frase, a revisar el escrito, etc. Lo importante es que al final del curso el alumno sea capaz de hacer eso, y no tanto que los textos que escriba no contengan incorrecciones. Con una metáfora excesivamente fácil, podríamos decir que el enfoque pretende enseñar a esculpir y no enseñar esculturas.

3) La programación recoge el conjunto de estrategias o habilidades y de actitudes respecto a lo escrito que caracterizan a un escritor competente. En definitiva, se trata de los procesos mentales que la psicología cognitiva ha aislado y calificado de fundamentales: generación de ideas, formulación de objetivos, organización de las ideas, redacción, revisión, evaluación, etc. Estos procesos forman los grandes bloques, apartados o lecciones de un curso, y para cada uno se enseñan varias técnicas útiles para la redacción. Así, en el capítulo de la generación de ideas se pueden enseñar técnicas como el torbellino de ideas, las analogías o comparaciones, la exploración sistemática de un tema a base de preguntas, etc.

A continuación, transcribo la lista de capítulos o lecciones del método de Flower (1985):

Paso $11^{\circ}$ : Explorar el problema retórico.

Paso 2.: Hacer un plan de trabajo.

Paso 3.: Generar ideas nuevas.

Paso $40^{\circ}$ : Organizar tus ideas.

Paso 5.: Conocer las necesidades de tu lector.

Paso 6.: Transformar prosa de escritor en prosa de lector *.

Paso $70^{\circ}$ : Repasar el producto y el propósito.

Paso 8.: Evaluar y corregir el escrito.

Paso 9.: Corrección de los conectores y de la coherencia.

El análisis individual de las necesidades del alumno es también muy importante en este enfoque. Según la teoría, no existe un único proceso correcto de composición de textos, sino que cada escritor ha desarrollado sus propias estrategias de acuerdo con sus habilidades, su carácter y su personalidad. Algunas investigaciones (Jensen y DiTiberio, 1984) han intentado relacionar factores de la personalidad (extroversión/introversión, pensar/sen-

* La prosa de escritor es lo que se escribe para uno mismo, mientras que la prosa de lector es lo que se escribe para otras personas. Ver Flower (1979) o Cassany (1987). 
tir...) con estilos cognitivos o estrategias de composición y han hallado algunas conexiones. Así, los individuos con tendencia a la extroversión prefieren técnicas como la escritura automática o libre (freewriting), o como el diálogo consigo mismos o con otros autores, y suelen escribir de una forma impulsiva y espontánea; mientras que los introvertidos utilizan los esquemas, las listas y el orden en el trabajo.

De esta forma, no se pueden enseñar «recetas" únicas de escritura, ni podemos esperar que las mismas técnicas sean válidas y útiles para todos. Cada alumno tiene que desarrollar su propio estilo de composición a partir de sus capacidades: tiene que superar los bloqueos que sufra, tiene que seleccionar las técnicas más productivas para él, saber integrarlas y adaptarlas a su forma de trabajar, tiene que rentabilizar el tiempo de composición, etc. Los profesores ayudan a sus pupilos analizando su forma de escribir y tomando conciencia con ellos de sus defectos y de las potencialidades, sugiriendo técnicas adecuadas para cada uno, corrigiendo su forma de trabajar, etc. En resumen, se trata de un trabajo muy individualizado con el sujeto de la escritura (y no con el objeto: el texto), que se asemeja bastante a la relación entre psicólogo y cliente.

4) Las clases basadas en este enfoque funcionan de una forma muy particular. Se parecen mucho a los conocidos Talleres de literatura o Talleres de expresión escrita (ver Auladell y Figuerola, 1989), aunque lo que escriben los alumnos no tiene que ser necesariamente literatura o textos con intención artística o lúdica, sino que pueden escribir cartas, trabajos escolares, ensayos, diarios íntimos, etc. Básicamente, se propone un tema y los alumnos se pasan todo el tiempo de clase escribiendo sobre él. El papel del profesor consiste en orientar y asesorar el trabajo del alumno: decirle cómo puede trabajar, qué técnicas puede utilizar, leer sus borradores y mostrarle los errores o los puntos flojos, etc.

De hecho, la clase puede adoptar diversas formas: Se puede trabajar de una manera más programada, con tareas e instrucciones precisas sobre lo que se tiene que hacer, colaborando en grupo, poniendo en común los resultados, etc.; o puede fluir espontáneamente según el ritmo y los intereses de cada alumno, sin ejercicios ni organización concretos, sólo con una tarea general muy abierta. Por ejemplo, dado un tema determinado, el profesor puede dar instrucciones detalladas cada diez o quince minutos sobre lo que se tiene que hacer para desarrollar el tema escrito: una lista de ideas, un esquema, un grupo de preguntas, un borrador, etc.; y los alumnos cumplen las instrucciones sucesivamente, al pie de la letra. Por otra parte, el tiempo de clase se puede convertir también en un espacio libre y autónomo para que cada uno escriba a su ritmo unos textos determinados de antemano a principio de curso, de trimestre o de mes (de forma muy parecida a como funciona el método Garrison, citado por Sokmen, 1988). En este caso, el profesor se convierte en un supervisor-colaborador del alumno, que pasea por el aula y responde a las dudas de los estudiantes.

Otro aspecto muy particular de este enfoque es la corrección de los trabajos de los alumnos. Según la teoría (Cassany, 1989), no se corrige el producto sino el proceso de redacción. No interesa tanto erradicar las faltas de gramática del escrito como que el alumno mejore sus hábitos de composición: que supere los bloqueos, que gane en agilidad, que rentabilice su tiempo, etc. De esta manera, la corrección supera con creces el marco lin- 
güístico y atañe campos psicológicos como la forma de pensar o estilo cognitivo, las técnicas o las destrezas de estudio, la creatividad, etc. En definitiva, ya no se habla de corrección sino de asesoramiento.

5) Con el enfoque basado en el proceso, el mismo ejercicio de otros capitulos pasaría a ser una tarea que requeriría muchas instrucciones y bastante más tiempo para realizarse:

1. Realiza un torbellino de ideas sobre el tema de las ventajas y las desventajas de vivir en un pueblo o en una ciudad. Apunta todo lo que se te ocurra. Tienes sólo 6 minutos.

2. Lee lo que has escrito y clasificalo en grupos de ideas distintas. Completa los grupos.

3. Desarrolla las ideas de dos de los grupos. Busca ejemplos y argumentos para cada idea.

4. Escribe un primer borrador de un texto titulado Ventajas y desventajas de vivir en un pueblo.

Con los ejercicios anteriores, se explicaba al alumno cómo debía ser el texto final que tenía que presentar: temas, extensión, tipo de texto, etc. Al contrario, de esta forma se muestra al alumno lo que tiene que hacer para conseguir el escrito: cómo puede conseguir ideas, cómo puede desarrollarlas, estructurarlas, etc. En este enfoque es más importante el proceso de trabajo del alumno que el producto final que consiga.

6) Pocos libros exponen en las lenguas ibéricas este enfoque desarrollado básicamente en Norteamérica. Desde un punto de vista teórico, destacan los volúmenes monográficos de Cassany (1987 y 1989) y el libro de Serafini (1985). Aunque breve, otro texto a tener en cuenta es La expresión escrita en la escuela. Enfoques metodológicos para un proyecto (1985), del Instituto de Estudios Pedagógicos Somosaguas. Los mejores cursos o libros prácticos que desarrollan este enfoque son Flower (1985) y Murray (1987), aunque se parezcan más a manuales de reflexión que a métodos de aprendizaje.

\section{ENFOQUE BASADO EN EL CONTENIDO}

1) Este enfoque se desarrolló paralelamente en dos contextos académicos distintos, en Estados Unidos durante la década de los ochenta: por una parte, en los cursos de escritura (writing) de las universidades y de los colleges; por otra, en las escuelas básicas y medias con el movimiento "escritura a través del currículum». En ambos casos, la idea fundamental que subyace es la supremacía del contenido por encima de la forma (sea ésta gramática, función, tipo de texto o proceso).

Respecto al primer contexto, los profesores de escritura de dichos centros de enseñanza superior elaboraron una metodología nueva para atender las características y las necesidades especiales de sus alumnos, estudiantes de universidad y futuros científicos. Esta metodología se basa en los puntos siguientes:

1. Las necesidades de expresión escrita de estos alumnos son básicamente académicas: exámentes, apuntes, trabajos, ensayos... Este tipo de textos presenta unas características muy específicas (investigaciones citadas por Shih, 1986). El siguiente esquema esboza las principales: 


\section{TEXTOS ACADEMICOS}

Ej.: trabajos, exámenes, resúmenes, recensiones, comentarios de texto, esquemas, apuntes, fichas, ponencias, comunicaciones, artículos, resenas, etc.

- El propósito de los textos es demostrar conocimientos (evaluación) o exponer los resultados de un trabajo (investigación).

- El contenido de los textos proviene de otros textos escritos o de actividades académicas (conferencias, clases, experimentos...).

- Utilizan un lenguaje altamente especializado y técnico.

- El destinatario del texto es siempre el mismo: el profesor. El texto requiere siempre un registro formal.

- Suele haber limitaciones importantes de tiempo en su elaboración.

\section{TEXTOS NO ACADEMICOS}

Ej.: cartas, diarios intimos, instancias, felicitaciones, avisos, notas, postales, anuncios, carteles, apuntes de agenda, etc.

- El propósito de los textos es muy variado: informar, agradecer, pedir, recordar, etc.

- El contenido proviene de la experiencia personal del autor.

- Utilizan un lenguaje general.

- El destinatario es variado y muy distinto según el texto, lo cual requiere la elección del registro apropiado.

- No suele haber limitaciones de tiempo.

En consecuencia, el dominio de la comprensión y de la producción de los textos académicos requiere un tipo de estrategias sustancialmente distintas a las necesarias para el dominio de los textos sociales, más generales. Y esto también implica un cambio en la didáctica de la enseñanza.

2. Asimismo, la necesidad de la expresión escrita nace con el interés y/o la obligación de realizar una carrera universitaria; o sea, con el interés por una determinada disciplina del saber, generalmente muy técnica y especializada. A los alumnos no les interesa escribir sobre temas generales como las vacaciones, los deportes o el ocio, sino que pretenden desarrollar sus ideas sobre ingeniería electrónica, química orgánica o informática. De este modo, los ejercicios de expresión escrita tienen que estar muy relacionados con el programa de estudios de los alumnos y, también, los profesores tienen que conocer la materia sobre la que escriben sus alumnos para poder corregir y ayudarles.

3. El interés por la expresión escrita está relacionado con el interés por otras habilidades lingüísticas como la lectura o la comprensión oral, así como con otras destrezas más abstractas como la selección de la información relevante, el resumen, la esquematización y el procesamiento general de la información, etc. Así, al tener que atender también a necesidades congnitivas más generales, a parte de las estrictamente lingüísticas, los ejercicios 
de expresión se convierten en tareas o proyectos muy complejos que requieren un trabajo intelectual importante.

En conjunto, se trata de un enfoque muy especializado en la enseñanza de las habilidades lingüísticas académicas. Se realiza en el contexto de los estudios superiores y utiliza ejercicios de tareas o proyectos sobre temas académicos.

En el segundo caso, el movimiento pedagógico llamado escritura a través del curriculum («writing across the curriculum»), se propone utilizar el potencial creativo que posee el proceso de composición de textos para enseñar otras materias. Se trata de que los alumnos escriban sobre temas de sociales, matemáticas o física, en la asignatura correspondiente, para que aprendan sobre estos temas, además de practicar y mejorar su expresión. De esta forma, la enseñanza de la expresión escrita rompe los límites de la asignatura de lengua y pasa a cubrir todo el currículum. Los dos principios fundamentales de este movimiento son los siguientes:

1. El proceso de composición de textos incluye de alguna forma un proceso de aprendizaje. Los escritores aprenden cosas sobre lo que escriben cuando escriben. Escribir es un instrumento de aprendizaje.

2. Este instrumento puede utilizarse para aprender sobre cualquier tema o asignatura del currículum. Los ejercicios de expresión escrita no sólo sirven para evaluar los conocimientos de los alumnos sobre un tema, sino que pueden utilizarse para aprender sobre este tema.

Griffin (1982) presenta de forma general los principales rasgos de estos movimientos pedagógicos y propone ejemplos de ejercicios en todo tipo de materias del currículum.

Otras experiencias didácticas muy relacionadas con este enfoque basado en el contenido son el trabajo organizado por tareas, o project work, desarrollado originalmente en la enseñanza del inglés como segunda lengua (ver The Reality of a Dream: An example of Project Work, 1988); y el conjunto de la disciplina - hoy muy de moda- de la metacognición: el autoaprendizaje, las técnicas de estudio, el aprender a aprender, etc. (Nisbet y Shucksmith, 1986, y Noguerol, 1989).

2) Las características principales del enfoque son las siguientes (Shih, 1986):

1. Se pone el énfasis en lo que dice el texto, en el contenido, y no en cómo se dice, en la forma. Interesan cuestiones como si las ideas son claras, si están ordenadas, si son originales, si se relacionan con argumentos sólidos, si son creativas, etc. Los aspectos formales de la expresión y del texto (estructura, presentación, gramática, etc.) no se incluyen en la programación del curso y sólo se tratan si el alumno presenta necesidades de este tipo.

2. No se escribe sobre la experiencia personal de cada uno, sino sobre algún tema académico. Las fuentes de la escritura son, pues, básicamente bibliográficas: libros, conferencias, apuntes, artículos, etc. De esta forma, la clase de expresión escrita se relaciona muy estrechamente con las disciplinas de contenido de la carrera.

3. La habilidad ( skill») de la expresión escrita se integra con las otras habilidades lingüisticas (escuchar, leer y hablar) en el contexto del trabajo académico. Se entiende que el desarrollo de una habilidad no se realiza aisladamente del aprendizaje global de las destrezas lingüísticas. Además, el 
tipo de actividades de estudio que tienen que realizar los alumnos en su carrera integra y entremezcla todas las habilidades. En consecuencia, en el aula los alumnos no sólo escriben, sino que practican todo tipo de ejercicios verbales.

4. En los ejercicios de clase, se distinguen dos secuencias muy claras y separadas. Una primera fase de estudio y comprensión de un tema (de «inputw) precede siempre la fase final de elaboración de ideas y producción de un texto escrito. En una primera etapa, el alumno se «sumerge» en el tema: lee artículos, escucha exposiciones sobre éste, comenta y discute el contenido con sus compañeros y su profesor, etc. En la etapa final, empieza a recoger información, a esquematizarla y a preparar sus ideas para un texto escrito.

3) En principio, la programación del curso se basa en el contenido de una o varias materias de estudio. Puede tratarse de un programa muy completo y estructurado a partir de un tema o una disciplina, o también podemos encontrar programaciones más flexibles que consisten en un simple listado de temas de interés de los alumnos. En este último caso, nos encontraríamos muy cerca de un planteamiento tan conocido como los famosos centros de interés del alumno.

Sin embargo, detrás de este simple listado de temas, atractivo y ameno, los profesores han organizado un conjunto muy variado de actividades (tareas, proyectos, trabajos, ejercicios, etc.) que responden a una variada gama de objetivos: practican todo tipo de habilidades lingüísticas, desarrollan estrategias cognitivas varias (análisis, comprensión, síntesis, valoración, etc.), utilizan tipos de texto muy distintos (orales/escritos, argumentativos/informativos, etc.) o obligan a trabajar de maneras diversas (en clase, en casa, en grupo, solo, en la biblioteca, etc.). Y no cabe duda que ésta es la verdadera programación del curso: un conjunto extraordinariamente variado de ejercicios que requieren todo tipo de esfuerzos por parte del alumno. Shih y Griffin ofrecen varias clasificaciones de habilidades o destrezas académicas que pueden ser la base de programas de expresión escrita.

4) Una clase basada en este enfoque incluye los pasos siguientes:

1. Investigación profunda de un tema (o, como dice Shih, incubación): lectura de textos, análisis de las tesis y los argumentos, búsqueda de nueva información, selección, etc.

2. Procesamiento de la información: elaboración de esquemas, discusiones en grupo, contraste de opiniones, etc.

3. Producción de escritos: preparación y redacción de textos académicos.

En general, el tipo de ejercicios que se realizan son muy globales. Parten de textos completos, no de frases o fragmentos; de documentos reales, sin manipulación, que no se han preparado especialmente para la enseñanza; y de material gráfico: esquemas, mapas, fotografías, etc. Los alumnos se fijan siempre en el contenido: extraen las ideas principales, comparan dos textos, interpretan un esquema, etc. $Y$ lo que tienen que producir son textos académicos reales: reseñas, ensayos, artículos para una revista de la escuela, comentarios de texto, etc.

Respecto a la corrección, destacan dos líneas básicas: atención primordial al contenido del texto e individualización para responder a las necesidades de cada alumno $\mathrm{y}$, también, para tratar de los aspectos formales. 
5) El ejemplo que nos sirve de contraste se convierte aquí en una auténtica tarea o trabajo que ocuparía muchas sesiones de trabajo:

1. Busca información en la biblioteca sobre la calidad de vida en Melgar de Abajo y en Madrid (o Valladolid).

2. Lee e interpreta los gráficos siguientes: número de hospitales, oferta cultural, contaminación, coste de la vivienda, precios... Reúne los datos principales en un resumen.

3. Escucha esta conferencia sobre el tema Calidad de vida en España y toma notas de los puntos importantes. Comenta los puntos más importantes con tus compañeros.

4. Revisa toda la documentación sobre el tema y escribe un pequeño artículo sobre tu investigación.

6) Dos buenos textos sobre este enfoque son los ya citados de Shih (1986) y Griffin (1982).

\section{EPILOGO}

No cabe duda que en cualquier acto de expresión escrita interviene la gramática, la función o el tipo de texto que se escribe, el proceso de composición del mismo, y la información o el contenido. Los cuatro aspectos son importantes e imprescindibles para el éxito de la comunicación. Asimismo, cualquiera de los enfoques didácticos expuestos incluye de alguna forma estas cuatro perspectivas de la expresión. Las diferencias entre uno y otro son cuestiones de enfoque y de énfasis. Cada metodología ahonda en un punto de vista y propone un trabajo prioritario y sistemático de éste.

Por estas mismas razones, los extremismos son muy peligrosos. Un enfoque que pretenda ser muy puro y basarse exclusivamente en un punto, corre el peligro de perder el resto y de vaciar de sentido el acto mismo de escritura. Algunos sufrimos en nuestra infancia el sinsentido, la inutilidad y el aburrimiento de un enfoque absolutamente gramatical, sin función, sin texto, sin proceso y con poco contenido. El resto de enfoques puede ser tan fatal como el primero, aunque mucho más modernos, si se utilizan de una forma radical. Creo que la sabiduría está en el eclecticismo. Cuando me imagino el mejor enfoque para un curso determinado, siempre me sale una mezcla rara de todas las posibilidades, algo que en cada caso intenta ser útil al alumno.

\section{Referencias}

ADAms, J. M. (1985). «Quels types de textes?» Le Français dans le Monde, n. ${ }^{0} 192$, abril.

AULADELL, J. y FIGUEROLA, J. (1989). Llançar-se a escriure. Barcelona: Sirius.

BORDONS; CASTELLÁ y MONNE (1988 y 1989). Trèvol text y Trèvol gramática, 1 y 2. Barcelona, Empúries y Universitat de Barcelona.

CASSANY; FAULl; McDowELl y ROCA (1987). Cop d'ull. Textos $i$ exercicis per a la comprensió lectora i l'expressió escrita. Barcelona: Edicions 62.

CASSANY, D. (1987). Descriure escriure. Com s'aprèn a escriure. Barcelona, Empúries (Versión castellana: Describir el escribir. Cómo se aprende a escribir. Barcelona: Paidós, 1989).

- (1989). Didáctica de la correcció del text escrit. Vic: EUMO.

COROMINA, E. (1984). Pràctiques d'expresió $i$ comunicació. Vic: EUMO.

- (1988). Tècniques d'expressió escrita. Barcelona: Teide (Versión castellana: Técnicas de comunicación. Barcelona, Teide, 1989). 
Equipo Avance (1986). Antena 1. Sociedad General Española de Librería.

Equipo Pragma (1983). Para empezar. Barcelona, Edi 6.

- (1985). Esto funciona. Barcelona, Edi 6.

FASSLER, B. et al. (1982). "Coaching the Process of Writing", en Griffin, C. Williams, ed. (1982), en esta misma bibliografía, pp. 3-14.

FLower, L. (1979). "Writer-Based-Prose: A Cognitive Basis for Problems in Writing». College English, 41 (Illinois), pp. 19-36.

- (1985). Problem-Solving Strategies for Writing. Brace Jovanovich (2. ed.).

GrIfFIN, C. ed. (1982): Teaching Writing in All Disciplines. San Francisco. Jossey-Bass Inc.

Jensen, G. H. y Ditiberio, J. K. (1984). *Personality and Individual Writing Processes». College Composition and Communication, vol. 35, n. 3 , octubre, pp. 285-300.

JOHNSON, K. (1981). Communicate in Writing. A functional approach to writing through reading comprehension. Libro del alumno y del profesor. Longman.

La expresión escrita en la escuela. Enfoques metodológicos para un proyecto (1985). Madrid. Departamento de Ciencias del Lenguaje del Instituto de Estudios Pedagógicos Somosaguas.

MurRaY, D. M. (1987). Write to Learn. Nueva York: Holt, Rinehart and Winston, Inc. (2.2 ed.).

Noguerol, A. (1989). Técniques d'aprenentatge $i$ estudi. Aprendre a l'escola. Barcelona, Graó.

NiSBET, J. y SHUCKSMITH, J. (1986). Leaming Strategies. Londres, Routledge \& Kegan Paul (Versión castellana de Ana Bermejo: Estrategias de aprendizaje. Madrid, Santillana).

The Reality of a Dream: An example of Project Work. (1988). L'ensenyament de les llengües estrangeres, recursos didàctics, 5 . Revista de la Generalitat de Catalunya.

SánChez; Cabré y Matilla. (1975). Español en directo. Madrid SGEL5.

SERAFINI, M. T. (1985). Come si fa un tema in classe. Milán Bompiani (Versión castellana de Rosa Premat: Cómo se redacta un tema. Didáctica de la escritura. Barcelona Paidós, 1989).

SHIH, M. (1986). "Content-Based Approaches to Teaching Academic Writing». TESOL Quarterly $X X, 4$, pp. 617-648.

SOKMEN, A. A. (1988), "Taking Advantage of Conference-Centered Writing". TESOL Newsletter, $22 / 1$, pp. 30-32.

\section{Enfoques didácticos para la enseñanza de la expresión escrita. D. Cassany. $C L E E, 1990,6$, pp. $63-80$}

\section{Resumen}

Pueden distinguirse cuatro enfoques metodológicos básicos en la enseñanza de los procesos superiores de la expresión escrita: un primer enfoque se basa en el estudio analitico de la estructura general de la lengua; el segundo propone un trabajo más bolístico de la comunicación, a partir de tipos de texto y de materiales reales; el tercer enfoque pone énfasis en el desarrollo del proceso de composición de textos escritos; finalmente, el cuarto se concentra en el contenido de los textos para aprovechar el potencial creativo y de aprendizaje de la expresión escrita. El presente articulo esboza las principales caracteristicas lingüisticas, didácticas y psicológicas de los cuatro enfoques, y lo bace de una forma mixta, enumerando las principales bases teóricas, explicando lo que pasa en el aula, y comparando varios ejemplos de cada enfoque.

Datos del autor: Profesor del departamento de filología catalana de la Escola Universitària de Formació del Professorat d'EGB de la Universitat de Barcelona. Ha publicado varios libros teóricos y prácticos sobre la enseñanza de la expresión escrita. Le interesa el estudio de las habilidades lingüísticas y la comunicación, y su aplicación práctica en la formación de profesorado y de personal no docente.

Dirección del autor: Daniel Cassany, Departament de Filologia Catalana, Escola Universitària de Formació del Profesorat d'EGB, c/ Melcior de Palau, 140. 08014 Barcelona.

(C) de todos los artículos. Deberá solicitarse por escrito autorización de CL\&E y de los autores para el uso en forma de facsímil, fotocopia y cualquier otro medio de reproducción impresa. CL\&E se reserva el derecho de interponer acciones legales necesarias en aquellos casos en que se contravenga la ley de derechos de autor. 